Stockdale, P. M. (1953). J. gen. Microbiol. 8, 434-441.

\title{
Requirements for the Growth and Sporulation of Trichophyton persicolor
}

\author{
BY PHYLLIS M. STOCKDALE \\ Department of Botany, University College of the South West \\ of England, Exeter
}

SUMMARY: The optimum temperature for the growth and sporulation of Trichophyton persicolor was $25-30^{\circ} ; 40^{\circ}$ inhibited growth. A range of $\mathrm{pH}$ values from 4 to 10 was compatible with growth, the optimum $\mathrm{pH}$ value being slightly less than $\mathrm{pH} 7$. Macroconidia were produced over a narrower range and were most abundant at $\mathrm{pH} 8$. Percentage germination and length of germ tube were greatest at $100 \%$ humidity. No germination occurred at humidities of below about 95\%. Exposure to light had no effect on growth rate, sporulation or pigmentation.

The carbon compounds which supported best growth were mannose, glucose, mannitol and maltose. Nitrates were not utilized, and ammonium sulphate, urea and asparagin supported poor growth. The amino-acids leucine, glycine, histidine and cysteine were utilized; with all other single amino-acids tested, growth was negligible. Methionine and phenylalanine were inhibitory.

T. persicolor was autotrophic for vitamins. It grew as well on a vitamin-free medium as on the basal medium.

The elements zinc, iron, copper and manganese, as sulphates, stimulated the growth and sporulation of $\boldsymbol{T}$. persicolor on a medium treated for the removal of trace elements.

This investigation arose from an observation that two isolates of Trichophyton persicolor (M2, isolated in France, and M3, isolated in Britain) grew yery differently from each other on Sabouraud's 'conservation' medium in which a peptic digest of meat replaced commercial peptone, while on Sabouraud's maltose 'proof' medium containing the same digest as nitrogen source their cultural appearance was similar. As no detailed investigation of the physiology of $T$. persicolor had been made previously it was decided to make a study of the nutritional and physico-chemical growth requirements of M2 and M3. Other isolates of $T$. persicolor were frequently included for comparison. Among these were one (M 323) from Dr R. Vanbreuseghem (Institut de Médecine Tropicale Prince-Léopold, Anvers), four (M 330, M332, M333 and M335) from Dr Jacqueline Walker (London School of Hygiene and Tropical Medicine) and two (S45 and S78) recently isolated from material sent to this laboratory.

No explanation of the difference between M2 and M3 has emerged during the course of this work, but an outstanding effect of environmental conditions of the production of macroconidia has been frequently noted.

T. persicolor Sabouraud (Les Teignes, 1910, p. 371) has been isolated only from human ringworm infections of the glabrous skin and there are few records outside western Europe. It has never been found to infect the hair or hair follicles of man or of experimentally inoculated guinea-pigs.

On sugar media such as beerwort agar or Sabouraud's glucose agar, cultures of the experimental isolates were granular, and light buff coloured, brownish 
in reverse. On such media they rapidly became pleomorphic, a white cottonwool-like mycelium overgrowing the colony. On Sabouraud's conservation medium (containing $30 \% \mathrm{w} / \mathrm{v}$ peptone but no sugar) the colonies were velvety and rose-violet, and in reverse deep wine colour. Microscopically, numerous microconidia ('en grappe' and 'en thyrse'), spirals, and chlamydospores were observed. Macroconidia, which were most abundant in older cultures, were large $(23 \times 4$ to $42 \times 7($ av, $35 \times 5) \mu$.), smooth and thin-walled. This appearance agrees well with that described by earlier workers (see Vanbreuseghem, 1949) except that no nodular organs were ever seen.

Apart from the production of a peach-coloured pigmentation on media of low sugar content, $T$. persicolor clearly closely resembles $T$. mentagrophytes, of which some workers consider it to be only a variant. However, T. persicolor has been regularly recorded in Europe since it was first described and does appear to merit a special designation. Here, the original name is adopted, but for those who prefer it, the combination Trichophyton mentagrophytes var. persicolor has been proposed by Magalhães (1935).

\section{METHODS}

The basal medium used for routine experiments was: $\mathrm{K}_{2} \mathrm{HPO}_{4}, 1.0 \mathrm{~g}$.; $\mathrm{KCl}$, 0.5 g.; $\mathrm{MgSO}_{4} .7 \mathrm{H}_{2} \mathrm{O}, 0.5 \mathrm{~g}$.; $\mathrm{FeSO}_{4} .7 \mathrm{H}_{2} \mathrm{O}, 0.01 \mathrm{~g}$.; glucose, $20 \cdot 0$ g.; peptone, $2 \cdot 2 \mathrm{~g}$.; distilled water to $1000 \cdot 0 \mathrm{ml}$. This is a modification of the Czapek-Dox solution, with peptone replacing the sodium nitrate at an equivalent nitrogen level and with glucose as the carbon source. The medium was sterilized by autoclaving at $10 \mathrm{lb} . / \mathrm{sq} . \mathrm{in}$. for $15 \mathrm{~min}$. The final $\mathrm{pH}$ value was $6 \cdot 4-6 \cdot 6$, which is approximately optimal, and therefore no adjustment was made.

For preliminary work solid medium was used, the basal medium being solidified with $2 \%$ agar. For more detailed quantitative studies the fungi were grown on $25 \mathrm{ml}$. volumes of liquid medium in $100 \mathrm{ml}$. Pyrex conical flasks. These cultures were incubated for 2 weeks at $25^{\circ}$ and the mycelium then filtered off on to dried, weighed filter-papers, washed with distilled water, and dried to constant weight at $100^{\circ}$. Each treatment was carried out in triplicate and each experiment repeated at least once. The macroscopic and microscopic appearance of the colonies and the final $\mathrm{pH}$ values were noted at the end of each experiment.

\section{RESULTS}

\section{Physico-chemical factors}

Temperature. The effects of temperature on growth were examined by incubating cultures on liquid and solid media at room temperature and at $20,25,30,35$ and $40^{\circ}$. Readings (dry weights or colony diameters) were taken at intervals of three days. The optimum temperature for the growth of both M2 and M3 during 4 weeks was $25-30^{\circ}$ and the development of micro- and macroconidia was most abundant in this range. At $35^{\circ}$ growth was very wrinkled, and numerous chlamydospores, but few or no conidia, were produced. Incubation at $40^{\circ}$ was inhibitory and prolonged exposure to this temperature was lethal; cultures transferred to $25^{\circ}$ after 2 weeks at $40^{\circ}$ did not 
grow. In this respect $T$. persicolor differed from a strain of $T$. mentagrophytes which grew best at $35^{\circ}$ and showed fairly good growth at $40^{\circ}$ (Fig. 1). Robbins \& Ma (1945) also found $35^{\circ}$ to be optimal for $T$. mentagrophytes.

Hydrogen-ion concentration. The $\mathrm{pH}$ value of the basal medium was adjusted most satisfactorily by the addition of sulphuric or tartaric acids for the lower $\mathrm{pH}$ values and of sodium carbonate for $\mathrm{pH} \mathrm{7-10.} \mathrm{These} \mathrm{substances} \mathrm{are}$ not utilized as nutrients by $T$. persicolor and are not toxic at the concentrations required. They held the $\mathrm{pH}$ value of the medium at a constant level for the duration of the experiment. When sodium hydroxide was used in place

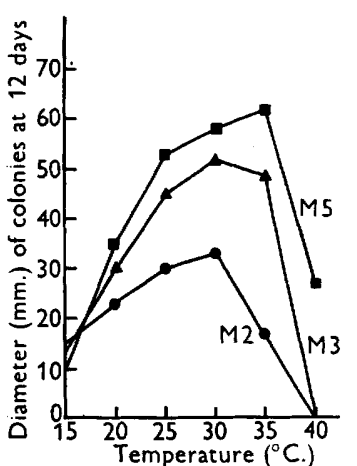

Fig. 1. Effect of temperature on growth of Trichophyton persicolor (M2, M3) and $T$. mentagrophytes (5)

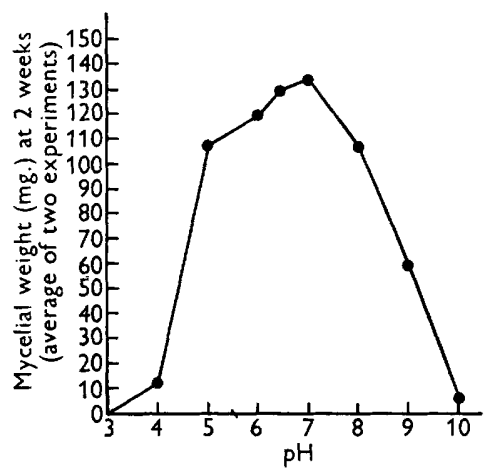

Fig. 2. Effect of $\mathrm{pH}$ value of medium color (M2).

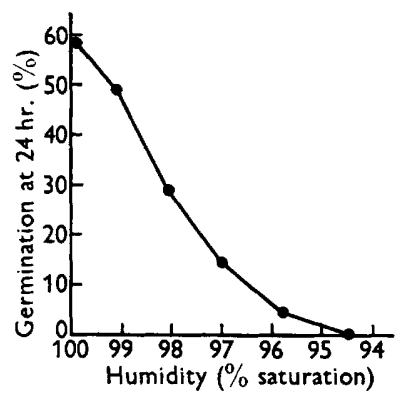

ig. 3. Effect of humidity on spore germination of Trichophyton persicolor (M2).

of sodium carbonate the $\mathrm{pH}$ value dropped rapidly because of the absorption of carbon dioxide from the atmosphere. This gave an abnormally high result for the growth in the alkaline range. Britton \& Wreford's citric acid and potassium dihydrogen phosphate buffers (Britton, 1932) were also found to be unsuitable. The $\mathrm{pH}$ value of the medium was adjusted as required by the use of a Cambridge $\mathrm{pH}$ meter or of a Lovibond comparator. The $\mathrm{pH}$ value of the medium at the beginning and end of each experiment was determined by means of the British Drug Houses Ltd. capillators.

Growth was studied over a range of $\mathrm{pH}$ values from 3 to 10 , at intervals of $1 \mathrm{pH}$ unit. $T$. persicolor resembled other dermatophytes in growing in a $\mathrm{pH}$ range of 4-10, the optimum being neutral to slightly acid (Fig. 2). At pH 4 and at $\mathrm{pH} 10$ growth was very poor and few or no microconidia were produced. Microconidium formation was greatest at the optimum $\mathrm{pH}$ value for growth. Macroconidia were produced over a smaller range, and were most abundant at $\mathrm{pH}$ 8. There was a striking increase in the formation of macroconidia by M2 and M3 with increasing $\mathrm{pH}$ value. This effect was also noted, though to a lesser extent, for other strains of $T$. persicolor, but not for isolates of $T$. mentagrophytes and Microsporum canis.

The reverse pigmentation of M2 and M3 in liquid culture changed from orange brown in acid to bright yellow in alkaline media. 
Humidity. The effect of humidity on spore germination was determined by using the technique devised by Davidson \& Gregory (1934). Spores of several strains of $T$. persicolor were placed on dry sterile cover-slips and inverted over van Tieghem cells in which the humidity was controlled by use of sucrose solutions of varying concentrations. The concentrations of sucrose and the resultant humidities were:

$\begin{array}{lrrrrrrr}\begin{array}{l}\text { Concentration of sucrose solution } \\ \text { (moles/l.) }\end{array} & 0.0 & 0.5 & 1.0 & 1.5 & 2.0 & 2.5 & 3.0 \\ \begin{array}{l}\text { Calculated humidity of atmosphere } \\ \text { (\% saturation) }\end{array} & \mathbf{9 9 . 9 2} & \mathbf{9 9 . 0 8} & 98.09 & \mathbf{9 6 . 9 9} & \mathbf{9 5 . 8 1} & \mathbf{9 4 . 6 0} & \mathbf{9 3 . 3 0}\end{array}$

The cells were incubated at $25^{\circ}$ and examined for germination after $24 \mathrm{hr}$. Results are shown in Fig. 3. Germination and length of germ-tube were greatest at $100 \%$ humidity (over pure water) and decreased rapidly with decreasing humidity. No germination occurred at humidities below about $95 \%$.

Light. Strains of $\boldsymbol{T}$. persicolor on Sabouraud's conservation medium, beerwort agar or basal agar were grown in complete darkness or in daylight. Examination after 1 month showed that exposure to light had no apparent effect on growth rate, pigmentation or spore production.

\section{Nutritional requirements}

Carbon. T. persicolor grew on the basal medium without any other carbon source than that provided by the peptone, but at the low concentrations of peptone used growth was greatly stimulated by the addition of certain carbon compounds. The following compounds were tested for their ability to support growth by using them in place of glucose in the basal medium at $20 \mathrm{~g}$. 1. ; the numbers in brackets following the names of the compounds are the dry weights in mg. of the mycelium of strain M2 obtained in one representative experiment on liquid medium in which the mycelial dry weight without added carbon was $8 \mathrm{mg}$. Pentoses: xylose (12), rhamnose (6); hexoses: glucose (130), mannose (146), galactose (18); disaccharides: sucrose (10), maltose (70), lactose (13); trisaccharide: raffinose (13); polysaccharides: starch, glycogen, cellulose (ashless filter paper); sodium salts of organic acids: acetate (8), citrate (7), tartrate; alcohols: glycerol (28), mannitol (92); glucoside: salicin (37).

The compounds which supported best growth, in order of availability, were thus : mannose $>$ glucose $>$ mannitol $>$ maltose. The weight of mycelium produced on maltose, the only disaccharide utilized, was only half that produced on glucose. Glycerol and salicin caused slight stimulation of growth of both M2 and M3, while galactose was utilized slightly by M3 only. All other compounds tested did not encourage greater growth than on the basal medium alone.

On media containing mannose, glucose or mannitol $T$. persicolor was buffcoloured and the $\mathrm{pH}$ value of the medium remained constant for the duration of the experiment. On all other media, including maltose, it was peachcoloured and the $\mathrm{pH}$ value rose to 8 , as on the medium without added carbon. 
On the salicin medium M2 always produced large numbers of macroconidia. This effect was not observed when salicin was added at concentrations of 1 or $10 \mathrm{~g}$./1. to Sabouraud's conservation or proof media, or to beerwort agar. Salicin did not stimulate the formation of macroconidia by other isolates of $T$. persicolor tested.

Thus $T$. persicolor does not differ markedly in its carbon nutrition from other dermatophytes. Mannose, glucose, mannitol and maltose have been found by other workers to support the growth of all species of dermatophytes tested; glycerol, salicin and galactose are not utilized so widely. A slight but definite utilization of sucrose was reported for $T$. interdigitale (Goddard, 1934; Mosher, Saunders, Kingery \& Williams, 1936) and for Microsporum canis (Goddard, 1934; Giblett \& Henry, 1950), but this was not observed in the present experiments.

The effect of varying the glucose:peptone ratio was studied over a range of concentration of $0-40 \mathrm{~g}$. glucose and $0-30 \mathrm{~g}$. peptone per litre. With increasing glucose concentration colonies became more spreading and pleomorphic. With increasing peptone they became more compact with a clearly defined edge and deep radial furrows. The formation of the peach-coloured pigment was controlled by the carbon: nitrogen ratio, increasing with increasing peptone and decreasing with increasing glucose. For example, at $40 \mathrm{~g}$. glucose $/ 1$. and $10 \mathrm{~g}$. peptone/l. (as in Sabouraud's proof medium) colonies of $T$. persicolor were cream-buff in colour while at $40 \mathrm{~g}$. glucose/l. and 20-30 g. peptone/l., they were deeply peach-coloured. Microconidia were produced in large numbers at all concentrations, but macroconidia were formed most abundantly at relatively high concentrations of peptone.

Nitrogen. The compounds sodium nitrate, ammonium sulphate, urea, and asparagine were tested for their ability to support the growth of M2 and M3 by using them in place of peptone in the basal medium at an equivalent level of nitrogen (i.e. equivalent to $330 \mathrm{mg}$. N/l.). Nitrate was not utilized and growth on media containing the other three compounds was very poor. Pleomorphic forms of $T$. mentagrophytes have been found to grow more readily than normal forms on ammonium media (Robbins \& Ma, 1945; Robbins \& McVeigh, 1946; McVeigh \& Campbell, 1950). Ammonium sulphate was almost completely unavailable for all of the 12 isolates of $T$. persicolor tested, including several pleomorphic forms. It was concluded, therefore, that nitrogen in the form of amino-acids was necessary for growth.

Growth was studied on the following amino-acids: $\beta$-alanine, glycine, Lhistidine $\mathrm{HCl}$, DL-valine, L-leucine, DL-methionine, DL- $\beta$-phenylalanine, L-cysteine, L-tyrosine, and monosodium glutamate. These were added to the basal medium singly in concentrations of $0 \cdot 2$ and $2 \cdot 0 \mathrm{~g}$. $/ 1$. When mixtures of the acids were used, the amounts of individual acids were such that the final total concentration of acids was $2 \cdot 0 \mathrm{~g}$. $/ \mathrm{l}$., divided equally among the acids in the mixture. Cystine and tyrosine are insoluble and were therefore added as suspensions.

Growth on each of the amino-acids at both concentrations was very poor. Leucine and glycine were the only acids which supported fair growth and 
sporulation, and there was an appreciable decrease when either was omitted from an otherwise complete mixture. Histidine and cysteine were utilized best at the lower concentrations. With all the other amino-acids growth was very poor and almost entirely subsurface in liquid media; no growth occurred with methionine or phenylalanine. A complete mixture was not very beneficial and there was an increase in growth when methionine and phenylalanine were omitted. These acids were thus apparently inhibitory at the concentrations used. A mixture of leucine, glycine, histidine and cysteine at a total concentration of $2.0 \mathrm{~g}$./l. was most beneficial (mycelial dry weight, $45.0 \mathrm{mg}$.), though growth on this did not approach that on peptone media (153.0 mg.).

These results agree fairly well with those of other workers. Leucine was found to be nearly indispensable for $T$. interdigitale (Mosher et al. 1936), and leucine and glycine were included by Robbins \& Ma (1945) among the acids which gave best growth of $T$. mentagrophytes. These authors also found that growth on methionine was very poor and a mixture of five amino-acids, including this one, was inhibitory. All of the dermatophytes studied by Archibald \& Reiss (1950), including T. mentagrophytes, grew very poorly on methionine alone. Phenylalanine was found by McVeigh \& Campbell (1950) to be toxic to $T$. mentagrophytes at $10.0 \mathrm{~g}$./l. (i.e. at an equivalent level of nitrogen to that supplied by $2 \mathrm{~g}$./l. asparagine).

Considerable variation was found between different brands of peptone. In one experiment the dry weight of mycelium produced by $\mathbf{M} 2$ on four different peptones was $43,72,86$ and $124 \mathrm{mg}$., respectively. Variation between different batches of the same brand was as great as that between different brands. The peptone used at the beginning of this investigation supported good growth of $T$. persicolor, but a later supply was completely unsatisfactory. When used in Sabouraud's conservation medium it gave rise to poor unpigmented colonies which were deeply folded and produced only chlamydospores. This emphasizes the need for a more complete knowledge of the nitrogen nutrition of dermatophytes.

Growth factors. $T$. persicolor grew as well on a basal medium containing vitamin-free casein hydrolysate as the nitrogen source as on a peptone medium. Yeast extract, added to vitamin-free casein hydrolysate, ammonium sulphate or asparagine media at concentrations of $0.01,0.1,0.2$ and $0.3 \%(w / v)$ stimulated growth. This stimulation was no greater than that caused by the addition of a quantity of vitamin-free casein hydrolysate containing an equivalent amount of nitrogen (micro-Kjeldahl). Addition to vitamin-free media of thiamine, nicotinic acid and riboflavin at a concentration of $500 \mu \mathrm{g} . / 1$., singly or in combination, did not stimulate growth. $T$. persicolor is thus apparently autotrophic for vitamins but requires organic nitrogen for growth. Isolates of T. mentagrophytes studied by Burkeholder \& Moyer (1943) and by Robbins \& Ma (1945) were also auxo-autotrophic, while the strain investigated by AreaLeão \& Cury (1950) required added thiamine and inositol.

Trace elements. Steinberg's method of removing trace elements was used (Steinberg, 1919). The basal medium was autoclaved at $15 \mathrm{lb} . / \mathrm{sq}$.in for $15 \mathrm{~min}$. with $15 \mathrm{~g}$. calcium carbonate/l. and was filtered hot through ashless filter-paper. 
All glassware was cleaned before use with chromic + sulphuric cleaning mixture and washed with glass-distilled water. The elements zinc, iron, copper and manganese, as sulphates, were added singly or in combination at concentrations of $0 \cdot 2,1 \cdot 0,5 \cdot 0$ and $20 \cdot 0$ parts of the element per million. In addition, the concentrations of these elements recommended by Steinberg for Aspergillus niger (i.e. $\mathrm{Zn}, 0 \cdot 18 ; \mathrm{Fe}, 0 \cdot 20 ; \mathrm{Cu}, 0 \cdot 04$; and $\mathrm{Mn}, 0.02$ p.p.m.) were used (from Foster, 1949). Batches of medium as made up were tested for removal of trace elements by growing on them a strain of $A$. niger which showed very poor colourless sporulation on a similarly treated medium containing ammonium nitrate in place of peptone.

Table 1. Trace element nutrition of Trichophyton persicolor

\begin{tabular}{|c|c|c|c|c|c|c|}
\hline & & & Exp & ent & & \\
\hline & 1 & 2 & 3 & 4 & 5 & 6 \\
\hline & & Aver & weight & rycel & mg.) & \\
\hline Treated & 21 & 171 & 143 & 31 & 86 & 94 \\
\hline Treated $+\mathrm{Mn}, \mathrm{Zn}, \mathrm{Fe}, \mathrm{Cu}$ & 101 & 150 & 126 & 123 & 2 & 121 \\
\hline Treated $+M n$ & 71 & 193 & 141 & 180 & 95 & 113 \\
\hline Treated $+\mathrm{Zn}$ & 68 & 184 & 174 & 173 & 91 & 127 \\
\hline Treated + Fe & 70 & 172 & 171 & 56 & 68 & 113 \\
\hline Treated $+\mathrm{Cu}$ & 55 & 130 & 120 & 83 & 83 & 104 \\
\hline
\end{tabular}

The results obtained were very inconsistent. In some experiments they were significant, growth being negligible in treated solutions without added trace elements and greatly stimulated by their addition. In other experiments the difference in weight on treated and untreated solutions was not very marked (Table 1). In all experiments the effect of the partial removal of trace elements on the appearance of growth and spore production of $T$. persicolor was very noticeable. Even when the growth rate was good on treated solutions the mycelium was almost entirely subsurface and no spores were produced. On treated media with added trace elements growth and sporulation were as good as on the untreated solution. The lowest concentrations of trace elements used were sufficient to meet the requirements of $T$. persicolor; there was no further increase of weight or of sporulation with further increased concentrations.

It was thought that inconsistencies in results might be due in part to the trace element content of the inoculum. Suspensions in glass-distilled water of fungi which had been cultivated on media 'free' from trace elements were therefore used for inoculation, and the effect of using very small amounts of inoculum was also determined. Results were no more constant when either of these precautions were taken. The variations were therefore presumably due to the difficulty in removing traces of elements from the peptone (see Donald, Passey \& Swaby, 1952). Solutions were also treated for removal of trace elements by passing them through a column of alumina. This had some effect, growth being greater on a treated medium to which elements had been 
added than on one without added elements, but the method was not so effective as Steinberg's.

Isolates of T. mentagrophytes (Robbins \& Ma, 1945; Robbins \& McVeigh, 1946; McVeigh \& Campbell, 1950) have been reported to grow well with nitrogen supplied as ammonium salts. Several isolates of this species and of $T$. persicolor were tested to see whether they grew well enough on ammonium sulphate media to enable their trace element nutrition to be studied on an inorganic medium. Growth of all isolates on such media was however negligible.

The only previous study of the trace element nutrition of dermatophytes I have found is that of Mosher et al. (1936), who claimed to have failed to obtain growth of $T$. interdigitale on a medium from which zinc, iron, copper and manganese were omitted. Details of their methods were not given, however. This aspect of the nutrition of dermatophytes requires further investigation.

This investigation was undertaken during the tenure of a Medical Research Scholarship awarded by the Court of the Grocer's Company, to whom I wish to express my thanks.

\section{REFERENCES}

Archibald, R. M. \& Reiss, F. (1950). Some biochemical implications from a study of growth of pathogenic fungi on media containing single amino-acids. Ann. N.Y. Acad. Sci. 50, 1388.

Arêa Leão, A. E. de \& Cury, A. (1950). Deficiencias Vitaminicas de Cogumelos Patogenico. Mycopathologia, 5, 5.

Britron, H. T. S. (1932). Hydrogen ions, 2nd ed. London: Chapman \& Hall.

Burkeholder, P. R. \& Moyer, D. (1943). Vitamin deficiencies of fifty yeasts and molds. Bull. Torrey bot. Cl. 70, 372.

Davidson, A. M. \& Gregory, P. H. (1934). In situ cultures of dermatophytes. Canad. J. Res. 10, 373.

Donald, C., Passey, B. I. \& Swaby, R. J. (1952). A comparison of methods for removing trace metals from microbiological media. J. gen. Microbiol. 7, 211.

Foster, J. E. (1949). Chemical activities of fungi. New York: Academic Press Inc.

GoDdard, D. R. (1934). Phases of the metabolism of Trichophyton interdigitale Priestly. J. infect. Dis. 54, 149.

Giblett, E. R. \& Henry, B. S. (1950). Physiological studies on the genus Microsporum. J. invest. Derm. 14, 377.

Magalhães, O. de (1935). Ensaios de mycologia. Mem. Inst. Osw. Cruz, 30, 1.

MCVeIGH, I. \& Campbeld, F. (1950). The growth of Trichophyton mentagrophytes and five of its variants as affected by several nitrogen sources. Mycologia, 42, 451.

Mosher, W. A., Saunders, D. H., Kingery, L. B. \& Williams, R. J. (1936). Nutritional requirements of the pathogenic mold Trichophyton interdigitale. Plant Physiol. 9, 795.

Robrins, W. J. \& MA, R. (1945). Growth factors for Trichophyton mentagrophytes. Amer. J. Bot. 32, 509.

Robbins, W. J. \& McVeigh, I. (1946). Effect of hydroxyproline on Trichophyton mentagrophytes and other fungi. Amer. J. Bot. 33, 638.

Steinberg, R. A. (1919). A study of some factors in the chemical stimulation in the growth of Aspergillus niger. Amer. J. Bot. 6, 330.

Vanbreuseghem, R. (1949). Contribution à la connaissance de Ctenomyces persicolor. Rapport d'un cas personnel. Ann. Parasit. hum. comp. 24, 124.

(Received 24, November 1952) 